\title{
Concentrados proteicos vegetais na alimentação de Jundiás (Rhamdia quelen)
}

\author{
Vegetable Protein concentrates in the diet of South American catfish Rhamdia quelen
}

\author{
Denize Tyska ${ }^{\mathrm{I}}$ Carlos Augusto Mallmann ${ }^{\mathrm{I}}$ Viviani Corrêia ${ }^{\mathrm{II}}$ Camila Durlo Tamiosso ${ }^{\mathrm{I}}$ \\ Adriano Olnei Mallmann ${ }^{\mathrm{I}}$ João Radünz Neto ${ }^{\mathrm{II}}$
}

\section{RESUMO}

O objetivo deste estudo foi avaliar fontes de concentrados proteicos vegetais alternativos em substituição ao farelo de soja sobre o desempenho e composição centesimal de jundiás (Rhamdia quelen) e coloração dos filés. Foram utilizadas 20 unidades experimentais, com capacidade de 90L cada uma, onde 400 peixes permaneceram alojados durante 45 dias. Os

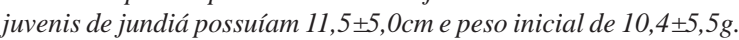
Foram avaliadas quatro fontes de concentrados proteicos, sendo eles: dieta controle, tendo o farelo de soja com base proteica; $C L$ : dieta contendo concentrado proteico de crambe + concentrado proteico de linhaça; CLGM: composta por concentrado proteico de crambe + concentrado proteico de linhaça + concentrado proteico de folha de mandioca + concentrado proteico de farelo de girassol e GM: constituída por concentrado proteico de farelo de girassol + concentrado proteico de folha de mandioca. Aos 30 e 45 dias, foram avaliados os parâmetros de crescimento (peso, fator de condição, taxa de crescimento específico, ganho em peso diário e relativo, taxa de eficiência proteica e conversão alimentar aparente) e avaliação centesimal do peixe inteiro e filé (umidade, proteína bruta, gordura e cinzas). Além disso, aos 45 dias, foi realizada a avaliação instrumental da cor nos filés. Ao final do período experimental, foram observadas diferenças significativas para os parâmetros de crescimento e avaliação centesimal, sendo que os animais alimentados com as dietas CL apresentaram maior crescimento $(13,8 \mathrm{~cm})$, taxa de crescimento específico (2,43\% dia $\left.{ }^{-1}\right)$, ganho em peso diário $\left(0,41 \mathrm{~g} \mathrm{dia}^{-1}\right)$, ganho em peso relativo $(108,3 \%)$ e menor conversão alimentar $(1,21)$, comparado às dietas contendo concentrado proteico de girassol e concentrado proteico de folhas de mandioca. Observou-se também que os animais alimentados com as dietas GM e CLGM apresentaram uma pigmentação amarelada nos filés. Conclui-se que os animais alimentados com a dieta CL obtiveram os maiores índices de desempenhos, podendo ser utilizada como alimento na formulação de dietas para esta espécie. As demais combinações não redundaram em resultados melhores que a dieta controle e CL. Palavras-chave: farelo de crambe, folha de mandioca, farelo
de girassol, farelo de linhaça, concentrados proteicos, filé, colorimetria.

\section{ABSTRACT}

The aim of this study was to evaluate vegetable protein concentrates to replace soybean meal (traditional protein) on performance and chemical composition of catfish (Rhamdia quelen) and its influence on the coloration of the fillets. We used 20 experimental units (EU), with a capacity of 90L each, where 400 fish were rearing for 45 days. Juvenile catfish had $11.5 \pm 5.0 \mathrm{~cm}$ and an initial weight of $10.4 \pm 5.5 \mathrm{~g}$. We evaluated four diets with different sources of protein concentrates, which are: Control, conventional diet using soybean meal as source of protein; CL: diet containing protein concentrate crambe meal protein concentrate; CLGM: protein concentrate consisting of crambe meal protein concentrate protein concentrate cassava leaf protein concentrate and GM sunflower meal: protein concentrate consisting of sunflower meal protein concentrate cassava leaf. At 30 and 45 days were evaluated growth parameters (weight, condition factor, specific growth rate, daily weight gain and relative protein efficiency ratio and feed conversion) and proximate evaluation of the whole fish and fillet (humidity, crude protein, fat and ash). In addition, the 45-day evaluation was made color instrumental in fillets. At the end of the experiment, significant differences were observed for growth parameters and proximate, and the animals fed the LC diets had higher growth $(13,8 \mathrm{~cm})$, specific growth rate $\left(2,43 \%\right.$ day $\left.^{-1}\right)$, daily weight gain $\left(0,41 \mathrm{~g} \mathrm{day}^{-1}\right)$, relative weight gain $(108,3 \%)$ and lower feed conversion $(1,21)$ compared to diets containing protein concentrate of sunflower and cassava leaves. We also observed that animals fed on GM diets and CLGM showed a yellowish pigment in the fillets. It is concluded that animals fed the CL diet had the highest levels of performance and can be used as food in the formulation of diets for this species. All others combinations do not showed no better results than the control diet and CL.

Key words: crambe meal, cassava leaf, sunflower meal, linseed meal, protein concentrate, fillet, colorimetry.

\footnotetext{
'Laboratório de Análises Micotoxicológicas (LAMIC), Departamento de Medicina Veterinária Preventiva (DMVP), Universidade Federal de Santa Maria (UFSM), Santa Maria, RS, Brasil.

IILaboratório de Piscicultura, Departamento de Zootecnia (DZ), UFSM, 97105-900, Santa Maria, RS, Brasil. E-mail: jradunzneto@yahoo.com.br.

*Autor para correspondência.
} 


\section{INTRODUÇÃO}

Vários ingredientes de origem vegetal apresentam potencial para substituir o farelo de soja em rações para peixes. Entre esses substitutos, constam fontes vegetais (ervilha, feijão, arroz, glúten de trigo, glúten de milho, tremoço e canola), além de subprodutos derivados da produção de biodiesel ou resíduo de culturas convencionais. Porém, como alguns desses ingredientes possuem limitantes nutricionais (taninos, glicosinolatos, fibras solúveis), existem algumas técnicas capazes de extrair os fatores antinutricionais através do uso de processamentos tecnológicos e com isso aumentar a disponibilidade de nutrientes, como a proteína (FERRI, 2006).

Com a grande demanda por produtos derivados da pesca, a preocupação em relação às dietas que serão fornecidas a esses animais aumenta. Apesar do aperfeiçoamento ocorrido nas últimas décadas na área da genética e manejo animal, o estudo sobre os aspectos nutricionais, especialmente relacionados a componentes essenciais da dieta (aminoácidos, fatores anti-nutricionais) é escasso e limitado a alguns ingredientes que se tornam muito onerosos ao produtor, como, por exemplo, a farinha de peixe (SANZ et al., 2000).

O farelo de soja é atualmente o ingrediente vegetal mais utilizado na formulação de dietas, devido ao seu valor proteico (44 a 50\% de proteína bruta), e adequado balanço de aminoácidos (GATLIN et al., 2007). Pode substituir até $50 \%$ da farinha de peixe em dietas para espécies carnívoras e até 94\% para onívoras (REFSTIE et al., 1998). O principal limitante à sua inclusão está relacionado à presença de fatores antinutricionais (inibidores de protease, ácido fítico, saponinas, lectinas) que interferem no aproveitamento dos nutrientes, causando redução no crescimento dos peixes (FRANCIS et al., 2001).

A busca por novas fontes alimentares tem focado as pesquisas em torno de proteínas vegetais alternativas, englobando culturas tradicionais e/ ou subprodutos, gerados a partir do beneficiamento de produtos in natura, como é o caso das indústrias de biodiesel. Porém, a maioria desses ingredientes possui algum tipo de limitação ao uso, como fatores antinutricionais e baixos níveis de aminoácidos essenciais. Assim, tem se buscado formas de minimizar esses limitantes através do uso de concentrados proteicos e, com isso, aumentar a biodisponibilidade dos componentes das matrizes nutricionais (FERRI, 2006).

Dessa forma, no presente estudo, objetivou-se avaliar o desempenho de jundiás
(Rhamdia quelen), empregando fontes proteicas em substituição ao farelo de soja, oriundas de ingredientes vegetais alternativos (farelo de crambe, semente de linhaça, folhas de mandioca e farelo de girassol), tratados através do método de extração proteica.

\section{MATERIAL E MÉTODOS}

O experimento foi conduzido durante 45 dias (fevereiro a março de 2011) nas instalações do Laboratório de Piscicultura, situado na Universidade Federal de Santa Maria (altitude 95m, 29 $43^{\prime} \mathrm{S}$, $53^{\circ} 42^{\prime} \mathrm{W}$ ). Foi utilizado um sistema de recirculação de água com 20 unidades experimentais (UE) de 90 litros cada uma, compostas por 20 animais, com densidade de estocagem de $2,5 \mathrm{~g} \mathrm{~L}^{-1}$. O sistema possuía dois filtros biológicos e a temperatura ambiental foi climatizada a $26^{\circ} \mathrm{C}$.

Foram utilizados 400 juvenis de jundiás (peso médio inicial de $11,5 \pm 5,0 \mathrm{~g}$ ). Os animais foram arraçoados três vezes ao dia $(8,12 \mathrm{e} 17 \mathrm{~h})$, sendo realizada a sifonagem da UE após as alimentações da manhã e tarde. A temperatura e o oxigênio dissolvido da água foram controlados diariamente e os demais parâmetros analisados duas vezes por semana. As médias dos parâmetros de qualidade da água, verificadas durante o período experimental foram: temperatura $25 \pm 1,1^{\circ} \mathrm{C}$; oxigênio dissolvido $6,3 \pm 0,5 \mathrm{mg} \mathrm{L}^{-1}$; amônia total $0,5 \pm 0,4 \mathrm{mg} \mathrm{L}^{-1}$; nitrito $0,002 \pm 0,0005 \mathrm{mg} \mathrm{L}^{-1}$; dureza $81,7 \pm 38,2 \mathrm{mg} \mathrm{L}^{-1}$ de $\mathrm{CaCO}_{3}$; alcalinidade $71,4 \pm 10,7 \mathrm{mg}$ $\mathrm{CaCO}_{3} \mathrm{~L}^{-1}$ e pH 7,1 $\pm 0,2$.

$\mathrm{O}$ delineamento experimental utilizado foi o inteiramente casualizado, constituído de quatro tratamentos e cinco repetições com 20 alevinos cada. Foram avaliadas quatro dietas peletizadas contendo diferentes fontes de concentrados proteicos, sendo eles: controle: tendo o farelo de soja com base proteica, com nível de inclusão de $36 \%$ na dieta; CL: concentradoproteico de crambe $(16,2 \%)+$ concentrado proteico de linhaça $(19,8 \%)$; CLGM: concentrado proteico de farelo de crambe $(11,8 \%)+$ concentrado proteico de farelo de linhaça $(5,8 \%)+$ concentrado proteico de farelo de girassol $(12,2 \%)+$ concentrado proteico de folha de mandioca $(6,2 \%)$ e GM: concentrado proteico de farelo de girassol $(16,0 \%)+$ concentrado proteico de folha de mandioca $(20,0 \%)$. Os níveis de inclusão dos concentrados nas dietas variaram conforme os resultados de proteína bruta e aminoácidos após a análise precedida de extração proteica. As dietas avaliadas foram formuladas a fim de serem isoproteicas e isoenergéticas, contendo $37 \%$ de proteína bruta e $3.200 \mathrm{kcal}$ de ED $\mathrm{kg}^{-1}$ seguindo MEYER \& FRACALOSSI (2004). Foram utilizadas 
quatro fontes proteicas em substituição ao farelo de soja, e a dieta controle utilizada foi baseada em uma formulação sugerida por LAZZARI et al. (2006) (Tabela 1). A quantidade de ração foi ajustada de 3,5$5 \% \mathrm{PV}$ no decorrer do experimento.

Visando à preparação dos ingredientes para o processo de extração proteica, inicialmente, as folhas de mandioca foram sobrepostas em bancada experimental e permaneceram secando à sombra durante dois dias, sendo revolvidas periodicamente. Após o término desse processo, as folhas foram separadas do talo e colocadas em estufa com circulação de ar, em temperatura de $40^{\circ} \mathrm{C}$ a fim de finalizar o processo de secagem. Para finalizar o processo de desidratação, o material folhoso foi triturado e acondicionado em sacos plásticos. $\mathrm{O}$ crambe primeiramente passou por um processo de moagem e extração da gordura (AOAC, 1995). Logo após, foi realizado o processo de extração proteica.

O farelo de girassol foi inicialmente moído e peneirado (600 micras) para realização do processo de extração da proteína. A semente da linhaça primeiramente foi moída para posterior extração da goma (MAIA et al., 1999). Essa foi extraída em água $1: 10(\mathrm{p} / \mathrm{v})$ sob temperatura de $60-80^{\circ} \mathrm{C}$ por duas horas e o processo de precipitação foi realizado com álcool. Após esse procedimento, o material foi colocado em estufa $\left(60^{\circ} \mathrm{C}\right)$ por um período de 48 horas para sua secagem. Após a secagem, a linhaça foi moída e realizado o processo de extração da gordura (AOAC, 1995).

Tabela 1 - Formulação das dietas com concentrados proteicos vegetais.

\begin{tabular}{|c|c|c|c|c|}
\hline \multirow{2}{*}{ Ingredientes $(\%)$} & \multirow[b]{2}{*}{ Controle } & \multirow[b]{2}{*}{ GM } & \multirow[b]{2}{*}{ CLGM } & \multirow[b]{2}{*}{$\mathrm{CL}$} \\
\hline & & & & \\
\hline Milho & 15,24 & 12,43 & 13,67 & 14,39 \\
\hline Concentrado proteico farelo girassol & - & 16,00 & 12,20 & - \\
\hline Concentrado proteico folha mandioca & - & 20,00 & 6,20 & - \\
\hline Concentrado proteico farelo crambe & - & - & 11,80 & 16,20 \\
\hline Concentrado proteico farelo linhaça & - & - & 5,80 & 19,80 \\
\hline Farelo de trigo & 6,00 & - & - & - \\
\hline Farinha de carne e ossos & 34,60 & 37,00 & 34,80 & 33,50 \\
\hline Farelo de soja & 36,00 & - & - & - \\
\hline Óleo de soja & 4,00 & 3,00 & 4,00 & 5,20 \\
\hline Mistura vitamínica e mineral $^{2}$ & 3,00 & 3,00 & 3,00 & 3,00 \\
\hline Cloreto de sódio & 0,50 & 0,50 & 0,50 & 0,50 \\
\hline Botylated hydroxytolueno & 0,02 & 0,02 & 0,02 & 0,02 \\
\hline L- lisina & - & 0,07 & 0,09 & 0,72 \\
\hline $\mathrm{DL}$ - metionina & 0,64 & 0,49 & 0,52 & 1,06 \\
\hline \multicolumn{5}{|l|}{ Nutrientes } \\
\hline Umidade (\%) & 7,60 & 6,90 & 8,60 & 7,30 \\
\hline Proteína Bruta & 34,70 & 32,30 & 33,40 & 33,30 \\
\hline Extrato etéreo & 12,30 & 14,60 & 15,80 & 19,80 \\
\hline Cinzas & 10,80 & 11,60 & 10,70 & 9,70 \\
\hline Cálcio & 1,90 & 2,40 & 1,80 & 1,80 \\
\hline Fósforo & 1,30 & 1,60 & 1,20 & 1,40 \\
\hline Fibra em Detergente Neutro ${ }^{3}$ & 20,30 & 26,82 & 24,45 & 21,02 \\
\hline Carboidratos Solúveis em Detergente Neutro ${ }^{3}$ & 23,60 & 17,20 & 16,90 & 15,40 \\
\hline Energia digestível $(\mathrm{kcal} / \mathrm{kg})^{3}$ & 3239 & 3226 & 3235 & 3211 \\
\hline Relação ED/PB (kcal/g) & 9,30 & 9,90 & 9,60 & 9,60 \\
\hline
\end{tabular}

\footnotetext{
${ }^{1}$ Dietas ajustadas a partir de LAZZARI et al. (2006).
}

${ }^{2}$ Composição da mistura vitamínica e mineral (por kg de produto): Ác. Fólico: 3000mg, Ác. Pantotênico: 30000mg, Cobalto: 20mg Cobre: 2000mg, Colina: $800000 \mathrm{mg}$, Ferro: 30000mg, Biotina: 500mcg, Iodo: 900mg, Manganês: 5000mg, Selênio: 100mg, Vit.A: 10000000UI, Vit. B1: 8000mg, Vit. B2: 10000mg, Vit. B6: 8000mg, Vit. B12: 20000mcg, Vit. C: 150000UI, Vit. D: 2000000UI, Vit. E: 150000mg, Vit. K: 6000UI, Zinco: 20000mg, Inositol $88000 \mathrm{mg}$, Niacina $60000 \mathrm{mg}$.

${ }^{3}$ Calculada a partir da composição dos ingredientes da dieta.

GM: Concentrado Proteico de Farelo de Girassol + Concentrado Proteico de Folha de mandioca;CLGM: Concentrado Proteico de Farelo de Girassol + Concentrado Proteico de Folha de mandioca + Concentrado Proteico de Farelo de Crambe + Concentrado Proteico de Linhaça. CL: Concentrado Proteico de Crambe + Concentrado Proteico de Linhaça. 
Os ingredientes acima citados foram pesados e acondicionados em liquidificador industrial. Utilizou-se uma proporção de folhas de mandioca e água destilada de 1:10 (p/v), para obtenção do suco e retirada da fibra. Para extração proteica do farelo de crambe, linhaça e girassol, utilizou-se a proporção de 1:3 (p/v). Os produtos foram liquidificados por aproximadamente 15 minutos três vezes consecutivas.

Após o término desse processo, o material passou por processo de filtragem para retirada da fibra e obtenção do suco. No extrato das folhas de mandioca, utilizou-se o método de extração ácida (DERENZO \& ALDEIA, 2000) no qual o pH passou por um ajuste até $\mathrm{pH} 4,5$. Os demais ingredientes foram extraídos pelo método do ponto isoelétrico (SMITH et al., 1946). Os pHs dos sucos extraídos foram ajustados com as soluções $\mathrm{HCl} 0,1 \mathrm{~N}$ e $\mathrm{NaOH}$ $0,1 \mathrm{~N}$. O precipitado foi mantido em repouso por aproximadamente 1 hora para que ocorresse o processo de separação da proteína e do sobrenadante. Após esse período, separou-se o sobrenadante do precipitado e esse foi colocado em estufa a $60^{\circ} \mathrm{C}$ por $24 \mathrm{~h}$ para secagem.

No primeiro dia experimental, oito animais foram abatidos (Benzocaína- 250 $\mathrm{mg} \mathrm{L}^{-1}$.) e utilizados para análise da composição centesimal do peixe inteiro. Aos 30 e 45 dias experimentais dois juvenis foram coletados por tratamento e abatidos para análise da composição corporal e outros oito animais retirados para coleta do filé e análise da cor. A coloração foi mensurada através de um fotocolorímetro Konica Minolta modelo CR - 400/410, avaliando a luz refletida pela amostra em comparação a uma placa de calibração padrão (branca).

Os dados obtidos sobre o crescimento, composição centesimal e parâmetros relacionados à cor foram submetidos à análise de variância (ANOVA). As diferenças entre as médias foram comparadas pelo teste de Tukey $(\mathrm{P} \leq 0,05)$, utilizando o pacote estatístico Statgraphics Centurion XV. II v. $8^{\circledR}$

\section{RESULTADOS E DISCUSSÃO}

Os dados zootécnicos referentes ao comprimento total $(\mathrm{CT})$, peso $(\mathrm{P})$, ganho em peso diário (GPD), taxa de crescimento específico (TCE), taxa de eficiência proteica (TEP), conversão alimentar aparente (CAA) aos 30 e 45 dias estão demonstrados na tabela 2. Foi possível observar, ao longo do período experimental, rejeição da ração nos tratamentos CLGM e GM. Embora neste trabalho não se tenham realizado análises referentes a possíveis resíduos relacionados a fatores antinutricionais, os resultados sugerem que esse possa ser um fator que interferiu negativamente na digestibilidade das rações. SILVA \& PEZZATO (2000) verificaram que o farelo de girassol e a farinha de mandioca possuem baixa atratopalatabilidade para Tilápia-do-Nilo. Segundo CORRÊA et al. (2004) e MELO (2005), as folhas de mandioca possuem antinutrientes como polifenóis e inibidores de proteases que acarretam sabor adstringente e menor digestibilidade proteica, diminuindo o crescimento dos animais.

Em relação à composição corporal, foi possível observar que a composição do peixe inteiro foi afetada significativamente pelos tratamentos (Tabela 3). Os peixes alimentados com as rações $\mathrm{CL}$ apresentaram os maiores índices de gordura corporal. O maior índice de gordura (11,3\%) e DGC $(2,13 \%)$ encontrado no peixe inteiro do tratamento CL podem ser explicados pelo fato de a dieta conter um teor mais elevado de gordura na ração (19,8\%). A inclusão de gordura na ração dos peixes pode levar a um aumento de gordura corporal, tendo relação com o nível de inclusão, isto é, quanto maior o nível de gordura dietária maior o depósito de gordura no peixe (WILSON, 2002; MEURER et al., 2003; JUSTI et al., 2003). Com um maior conteúdo lipídico, essas espécies são mais susceptíveis à oxidação e à hidrólise enzimática dos ácidos graxos, causando perdas por ranço, colorações anormais e, consequentemente, menor vida de prateleira (SHARMA et al., 2000). Observou-se também que esse tratamento teve a maior DPC $(3,15 \mathrm{~g})$.

Outra variável que apresentou diferença significativa foi a umidade. Segundo BADOLATO et al. (1994), o principal componente do músculo do pescado é a água, seguido pela proteína e gordura, apresentando quantidades insignificantes de carboidratos. O conteúdo de lipídios é o mais variável, tanto no teor total quanto no tipo e proporção de ácidos graxos que o compõem. Embora a composição do pescado esteja bem estabelecida quanto aos seus constituintes predominantes, a proporção entre eles é extremamente variável (MAIA et al., 1999).

$\mathrm{Na}$ avaliação da composição centesimal do filé (Tabela 3), observou-se que os tratamentos GM e $\mathrm{CL}$ apresentaram os maiores índices de gordura. Com relação à proteína bruta e teor de cinzas e umidade, não houve diferença estatística entre os tratamentos.

Os maiores índices de gordura encontrados no filé dos animais alimentados com a dieta GM pode estar relacionado ao metabolismo dos aminoácidos. Após a ingestão e hidrólise, o excesso de aminoácidos é rapidamente desaminado, liberando amônia para excreção, esqueletos carbônicos para oxidação e 
Tabela 2 - Parâmetros zootécnicos dos jundiás alimentados com concentrados proteicos na dieta.

\begin{tabular}{|c|c|c|c|c|c|}
\hline Variáveis & Controle & $\begin{array}{c}\text { GM } \\
\text { Inicial }\end{array}$ & CLGM & CL & $d p r^{1}$ \\
\hline Peso (g) & $11,60 \pm 0,10$ & $11,40 \pm 0,10$ & $11,30 \pm 0,10$ & $11,50 \pm 0,10$ & 1,40 \\
\hline $\mathrm{CT}(\mathrm{cm})$ & $10,40 \pm 0,06$ & $10,30 \pm 0,06$ & $10,30 \pm 0,06$ & $10,40 \pm 0,06$ & 0,60 \\
\hline Peso (g) & $24,60^{c} \pm 0,54$ & $18,90^{\mathrm{a}} \pm 0,54$ & $21,60^{\mathrm{b}} \pm 0,54$ & $24,00^{\mathrm{c}} \pm 0,54$ & 5,40 \\
\hline $\mathrm{CT}(\mathrm{cm})^{2}$ & $13,20^{\mathrm{c}} \pm 0,11$ & $12,20^{\mathrm{a}} \pm 0,11$ & $12,70^{\mathrm{b}} \pm 0,11$ & $12,90^{\mathrm{bc}} \pm 0,11$ & 1,10 \\
\hline $\mathrm{TCE}^{2}(\% /$ diaa $)$ & $2,50^{\mathrm{a}} \pm 0,10$ & $1,60^{\mathrm{b}} \pm 0,10$ & $2,20^{\mathrm{a}} \pm 0,10$ & $2,40^{\mathrm{a}} \pm 0,10$ & 0,20 \\
\hline $\mathrm{GPD}^{2}(\mathrm{~g} / \mathrm{dia})$ & $0,40^{\mathrm{b}} \pm 0,02$ & $0,20^{\mathrm{a}} \pm 0,02$ & $0,31^{\mathrm{ab}} \pm 0,02$ & $0,40^{\mathrm{b}} \pm 0,02$ & 0,06 \\
\hline $\mathrm{GPR}^{2}(\%)$ & $111,30^{\mathrm{b}} \pm 7,48$ & $64,1^{\mathrm{a}} \pm 7,48$ & $84,6^{\mathrm{ab}} \pm 7,48$ & $108,3^{\mathrm{b}} \pm 7,48$ & 16,7 \\
\hline $\mathrm{FC}^{2}$ & $1,07 \pm 0,02$ & $1,03 \pm 0,02$ & $1,00 \pm 0,02$ & $1,10 \pm 0,02$ & 0,06 \\
\hline $\mathrm{CAA}^{2}$ & $1,40 \pm 0,16$ & $1,85 \pm 0,16$ & $1,63 \pm 0,16$ & $1,20 \pm 0,16$ & 0,40 \\
\hline $\mathrm{TEP}^{2}$ & $2,50^{\mathrm{b}} \pm 0,14$ & $1,70^{\mathrm{a}} \pm 0,14$ & $1,97^{\mathrm{ab}} \pm 0,14$ & $2,50^{\mathrm{b}} \pm 0,14$ & 0,30 \\
\hline Peso (g) & $31,10^{c} \pm 0,92$ & $\begin{array}{l}20,60^{\mathrm{a}} \pm 0,93 \\
20,60^{\mathrm{a}} \pm 0,93\end{array}$ & $24,50^{\mathrm{b}} \pm 0,92$ & $28,70^{\mathrm{c}} \pm 0,92$ & 8,00 \\
\hline $\mathrm{CT}(\mathrm{cm})$ & $15,60^{\mathrm{b}} \pm 0,16$ & $12,80^{\mathrm{a}} \pm 0,17$ & $\begin{array}{l}13,30^{\mathrm{ab}} \pm 0,16 \\
13,30^{\mathrm{ab}} \pm 0,16 ?\end{array}$ & $13,80^{\mathrm{ab}} \pm 0,16$ & 1,45 \\
\hline TCE (\%/dia) & $2,20^{\mathrm{c}} \pm 0,10$ & $1,30^{\mathrm{a}} \pm 0,10$ & $\begin{array}{l}1,72^{\mathrm{ab}} \pm 0,10 \\
1,72^{\mathrm{ab}} \pm 0,10 ?\end{array}$ & $2,00^{\mathrm{bc}} \pm 0,10$ & 0,22 \\
\hline GPD (g/dia) & $0,40^{\mathrm{c}} \pm 0,03$ & $0,20^{\mathrm{a}} \pm 0,03$ & $\begin{array}{l}0,30^{\mathrm{ab}} \pm 0,03 \\
0,29^{\mathrm{ab}} \pm 0,03\end{array}$ & $0,40^{\mathrm{bc}} \pm 0,03$ & 0,22 \\
\hline GPR (\%) & $166,10^{\mathrm{b}} \pm 12,1$ & $80,0^{\mathrm{a}} \pm 12,1$ & $117,70^{\mathrm{ab}} \pm 12$ & $144,30^{\mathrm{b}} \pm 12,1$ & 27,2 \\
\hline $\mathrm{FC}$ & $1,04 \pm 0,02$ & $1,00 \pm 0,02$ & $1,05 \pm 0,02$ & $1,10 \pm 0,02$ & 0,05 \\
\hline CAA & $0,80^{\mathrm{a}} \pm 0,02$ & $0,98^{\mathrm{b}} \pm 0,02$ & $\begin{array}{l}1,30^{\mathrm{b}} \pm 0,11 \\
0,87^{\mathrm{ab}} \pm 0,02\end{array}$ & $0,80^{\mathrm{a}} \pm 0,02$ & 0,06 \\
\hline TEP & $3,90^{\mathrm{b}} \pm 0,16$ & $3,00^{\mathrm{a}} \pm 0,16$ & $\begin{array}{l}3,40^{\mathrm{ab}} \pm 0,16 \\
3,45^{\mathrm{ab}} \pm 0,16\end{array}$ & $3,90^{\mathrm{b}} \pm 0,16$ & 0,30 \\
\hline
\end{tabular}

Valores expressos como média \pm erro padrão da média, na matéria natural.

Médias seguidas de letras diferentes na linha diferem estatisticamente pelo teste de Tukey.

${ }^{1}$ dpr: desvio padrão residual $(\mathrm{P}<0,05)$.

${ }^{2}$ Variáveis: comprimento total (CT); taxa de crescimento específico (TCE $\left(\%\right.$ dia $\left.^{-1}\right)$ : TCE $\left.=[(\ln \mathrm{PF}-\ln \mathrm{PI}) / \mathrm{d}] * 100\right)$; ganho em peso diário $\left(\mathrm{GPD}\left(\mathrm{g} \mathrm{dia}^{-1}\right)=(\mathrm{PF}-\mathrm{PI}) / \mathrm{d}\right)$; ganho em peso relativo $\left(\mathrm{GPR}(\%)\right.$ : GPR $=[(\mathrm{PF}-\mathrm{PI}) / \mathrm{PI}]^{*} 100$; em que: $\ln =$ logaritmo neperiano, $\mathrm{PF}=$ peso final, $\mathrm{PI}=$ peso inicial, $\mathrm{d}=$ período experimental, em dias); fator de condição $\left(\mathrm{FC}=\mathrm{P} /\left(\mathrm{CT}^{3}\right)^{*} 100\right)$; conversão alimentar aparente $\left(\mathrm{CAA}\left(\mathrm{kg} \mathrm{kg}^{-1}\right)=(\mathrm{ACt} / \mathrm{GPT})\right)$; taxa de eficiência proteica (TEP = ganho em peso $(\mathrm{g})$ /quantidade de proteína consumida $(\mathrm{g})$ ).

Tratamentos: GM: Concentrado Proteico de farelo de Girassol + Concentrado Proteico de Folha de mandioca; CLGM: Concentrado Proteico de farelo de Girassol + Concentrado Proteico de Folha de mandioca + Concentrado Proteico de farelo de Crambe + Concentrado Proteico de Linhaça; CL: concentrado proteico de farelo de crambe + concentrado proteico de farelo de linhaça.

produção de energia, ou, em alguns casos, conversão em glicose ou lipídeos (WALTON et al., 1995). Com relação a este parâmetro, neste trabalho, acreditase que a proteína foi desaminada e convertida em gordura de reserva.
Outro fator que pode ser afetado diretamente pela composição da dieta é a qualidade do filé, sendo esse um critério fundamental na escolha do consumidor. Com relação aos parâmetros de cor, foi observada diferença em todas as variáveis $\left(L^{*}, a^{*}\right.$, 
Tabela 3 - Composição centesimal do peixe inteiro e filés de jundiás alimentados com concentrados proteicos no início e aos 45 dias experimentais.

\begin{tabular}{|c|c|c|c|c|c|c|}
\hline \multirow{2}{*}{ Variáveis } & \multirow[b]{2}{*}{ Inicial } & \multirow[b]{2}{*}{ Controle } & \multirow[b]{2}{*}{ GM (2) } & \multirow[b]{2}{*}{ CLGM } & \multirow[b]{2}{*}{ CL } & \multirow[t]{2}{*}{$\mathrm{dpr}^{1}$} \\
\hline & & & & & & \\
\hline Umidade (\%) & $74,40 \pm 0,54$ & $77,07^{\mathrm{b}} \pm 1,20$ & $73,62^{\mathrm{ab}} \pm 1,0$ & $71,44^{\mathrm{a}} \pm 1,0$ & $71,86^{\mathrm{a}} \pm 1,1$ & 2,46 \\
\hline Cinzas $(\%)$ & $2,90 \pm 0,53$ & $2,97 \pm 0,26$ & $2,42 \pm 0,32$ & $2,94 \pm 0,18$ & $3,00 \pm 0,22$ & 0,45 \\
\hline Gordura (\%) & $6,53 \pm 0,46$ & $6,72^{a} \pm 0,76$ & $7,11^{\mathrm{a}} \pm 0,85$ & $7,57^{\mathrm{a}} \pm 0,69$ & $11,30^{\mathrm{b}} \pm 0,69$ & 1,71 \\
\hline Proteína (\%) & $12,90 \pm 0,39$ & $12,24 \pm 1,5$ & $12,24 \pm 1,5$ & $12,15 \pm 1,2$ & $15,40 \pm 1,2$ & 2,72 \\
\hline CRP $(\%) 2$ extenso & - & $18,7^{\mathrm{c}} \pm 1,0$ & $10,78^{\mathrm{a}} \pm 1,0$ & $14,16^{\mathrm{ab}} \pm 1,0$ & $18,32^{\mathrm{bc}} \pm 1,0$ & 2,44 \\
\hline $\mathrm{DPC}(\mathrm{g}) 2$ & - & $2,32^{\mathrm{b}} \pm 0,1$ & $1,05^{\mathrm{a}} \pm 0,1$ & $1,52^{\mathrm{a}} \pm 0,1$ & $3,15^{\mathrm{c}} \pm 0,1$ & 0,41 \\
\hline DGC(g) & - & $1,75^{\mathrm{b}} \pm 0,1$ & $0,64^{\mathrm{a}} \pm 0,1$ & $0,84^{\mathrm{a}} \pm 0,1$ & $2,13^{\mathrm{b}} \pm 0,1$ & 0,22 \\
\hline Umidade (\%) & - & $79,20 \pm 0,95$ & $76,70 \pm 0,60$ & $80,00 \pm 0,95$ & $79,09 \pm 0,95$ & 1,34 \\
\hline Cinzas (\%) & - & $1,03 \pm 0,12$ & $1,22 \pm 0,12$ & $0,97 \pm 0,12$ & $0,88 \pm 0,12$ & 0,17 \\
\hline Gordura (\%) & - & $3,67^{\mathrm{a}} \pm 0,18$ & $5,14^{\mathrm{c}} \pm 0,18$ & $4,07^{\mathrm{ab}} \pm 0,18$ & $4,63^{\mathrm{bc}} \pm 0,18$ & 0,31 \\
\hline Proteína (\%) & - & $13,86 \pm 0,90$ & $14,06 \pm 0,90$ & $13,56 \pm 0,90$ & $15,90 \pm 0,90$ & 1,28 \\
\hline $\mathrm{L}^{*}$ & - & $51,64^{\mathrm{a}} \pm 0,39$ & $58,11^{\mathrm{c}} \pm 0,38$ & $54,97^{\mathrm{b}} \pm 0,38$ & $52,41^{\mathrm{a}} \pm 0,39$ & 2,62 \\
\hline$a^{*}$ & - & $11,06^{\mathrm{c}} \pm 0,29$ & $9,12^{\mathrm{a}} \pm 0,29$ & $6,32^{\mathrm{a}} \pm 0,29$ & $5,66^{\mathrm{b}} \pm 0,29$ & 1,99 \\
\hline$b^{*}$ & - & $10,22^{\mathrm{a}} \pm 0,30$ & $17,36^{\mathrm{c}} \pm 0,29$ & $14,55^{b} \pm 0,29$ & $10,37^{\mathrm{a}} \pm 0,30$ & 2,02 \\
\hline$c^{*}$ & - & $15,10^{\mathrm{b}} \pm 0,32$ & $18,42^{\mathrm{c}} \pm 0,32$ & $15,95^{\mathrm{b}} \pm 0,32$ & $13,90^{\mathrm{a}} \pm 0,32$ & 2,19 \\
\hline$h^{*}$ & - & $43,02^{\mathrm{a}} \pm 0,94$ & $71,62^{\mathrm{d}} \pm 0,92$ & $66,22^{c} \pm 0,92$ & $49,13^{\mathrm{b}} \pm 0,94$ & 6,33 \\
\hline
\end{tabular}

Valores expressos como média \pm erro padrão da média, na matéria natural.

Médias seguidas de letras diferentes na linha diferem estatisticamente pelo teste de Tukey $(\mathrm{P}<0,05)$.

${ }^{1}$ dpr: desvio padrão residual.

${ }^{2}$ Variáveis: coeficiente de retenção proteica (CRP $(\%)=100 *[(\mathrm{P} * \mathrm{PBCf})-(\mathrm{Pi} * \mathrm{PBCi})] /(\mathrm{AC}$ por peixe*PBd)); deposição de proteína corporal $(\mathrm{DPC}(\mathrm{g})=[\mathrm{Pf} *(\% \mathrm{PBCf} / 100)]-[\mathrm{Pi} *(\% \mathrm{PBCi} / 100)]) ; \mathrm{DGC}$ : deposição de gordura corporal $(\mathrm{DGC}(\mathrm{g})=[\mathrm{Pf} *(\% \mathrm{GCf} / 100)]-[\mathrm{Pi} *(\% \mathrm{GCi} / 100)])$;

$L^{*}$ : luminosidade; $a^{*}$ : direção do vermelho para o verde; $b^{*}$ : direção do azul para o amarelo; $\mathrm{c}^{*}$ : croma; $\mathrm{h}^{*}$ :ângulo de tonalidade.

GM: Concentrado Proteico de farelo de Girassol + Concentrado Proteico de Folha de mandioca; CLGM: Concentrado Proteico de farelo de

Girassol + Concentrado Proteico de Folha de mandioca + Concentrado Proteico de farelo de Crambe + Concentrado Proteico de Linhaça;

CL: concentrado proteico de farelo de crambe + concentrado proteico de farelo de linhaça.

$\left.\mathrm{b}^{*}, \mathrm{c}^{*} \mathrm{e} \mathrm{h*}\right)$. O valor de $\mathrm{L}^{*}$ foi mais elevado para a dieta GM, ou seja, há uma maior tendência em direção à cor branca. Isso pode ser reflexo do maior teor de gordura observado no filé desse tratamento.

Dados semelhantes foram encontrados por LOSEKANN et al. (2008), avaliando três fontes lipídicas com inclusão de 5 e $10 \%$ na dieta de jundiás (Rhamdia quelen). Os valores de $\mathrm{L}^{*}$ encontrados foram superiores $(95,08)$ para o tratamento com maior nível de lipídeo (10\%).

Os valores de $a^{*}, b^{*}$ e $c^{*}$ apresentaram o mesmo comportamento, sendo que as dietas GM e CLGM apresentaram uma forte tendência em direção à cor amarela. Isso pode ser atribuído à presença da folha de mandioca na constituição dessas dietas. As folhas de mandioca contêm significativos níveis de carotenoides que contribuem na pigmentação (ADEWUSI \& BRADBURY, 1993). SKONBERG et al. (1998) avaliaram filés crus de truta arcoíris (Oncorhynchus mykiss) alimentadas com uma dieta a base de glúten de milho. Os valores de $b^{*}$ (cor amarela) foram maiores e receberam significativamente baixos escores de aceitação visual do que filés dos tratamentos com glúten de trigo. A coloração do filé é uma questão importante a ser considerada, já que a preferência do consumidor parece estar mais voltada a uma coloração branca a rósea, como no caso do salmão.

\section{CONCLUSÃO}

A dieta CL proporciona maior crescimento, comparada às dietas contendo concentrado proteico de folhas de mandioca e girassol, porém promove maior teor de gordura no peixe inteiro e filé. A coloração dos filés foi afetada pelas fontes proteicas, sendo que o tratamento com concentrado proteico de folha de mandioca resultou em pigmentação amarelada nos filés.

\section{COMITÊ DE ÉTICA E BIOSSEGURANÇA}

Parecer $n^{\circ}$ 054/2011. 


\section{REFERÊNCIAS}

ADEWUSI, S.R.A.; BRADBURY, J.H. Carotenoids in Cassava: comparation of open column and HPLC methods of analysis. Journal of Science Food Agricultural, London, v.62, p.375-383, 1993

AOAC. (ASSOCIATION OF OFFICIAL ANALYTICAL CHEMISTS). Official methods of analysis of AOAC. 16.ed. Washington, DC: Patricia Cunniff, 1995. 1141p.

BADOLATO, E.S.G. et al. Composição centesimal de ácidos graxos e valor calórico de cinco espécies de peixes marinhos nas diferentes estações do ano. Revista do Instituto Adolfo Lutz, São Paulo, v.54, n.1, p.27-35, 1994.

CORRÊA, A.D. et al. Remoção de polifenóis da farinha de folhas de mandioca. Ciência e Tecnologia de Alimentos, Campinas, v.24, n.2, p.159-164, 2004

DERENZO, S.; ALDEIA, W. Estudo das condições operacionais da etapa de extração de proteína do capim elefante (Pennisetum purpureum schum), utilizado como fonte energética. In: ENCONTRO DE ENERGIA NO MEIO RURAL, 3., 2000, Campinas, SP. Proceedings... (online). Disponível em: $<$ http:// www.proceedings.scielo.br/scielo>. Acesso em: 25 ago. 2011

FERRI, P. Extração de proteínas de folhas de mandioca (Manihot esculenta Crants) para obtenção de concentrado protéico. 2006. 112f. Dissertação (Mestrado em Engenharia Agrícola) - Universidade Estadual do Oeste do Paraná (Unioeste), Cascavel, PR.

FRANCIS, G. et al. Antinutritional factors present in plantderived alternate fish feed ingredients and their effects in fish. Aquaculture, Amsterdam, v.199, p.197-227, 2001.

GARCIA, S.M.; DE LEIVA MORENO, I. Global overview of marine fisheries. In: CONFERENCE RESPONSIBLE FISHERIES IN THE MARINE ECOSYSTEM, 2001, Reykjavic. Proceedings... Disponível em: <ftp://ftp.fao.org/fi/document/ reykjavik/pdf/01garcia.pdf>. Acesso em: 30 ago. 2012.

GATLIN, D.M. et al. Expanding the utilization of sustainable plant products in aquafeeds: a review. Aquaculture Research, v.38, p.551-579, 2007.

JUSTI, K.C. et al. The influence of feed supply time on the fatty acid profile of Nile tilapia (Oreochromis niloticus) fed on a diet enriched with n-3 fatty acids. Food Chemistry, v.80, p.489-493, 2003.

LAZZARI, R. et al. Diferentes fontes protéicas para a alimentação do jundiá (Rhamdia quelen). Ciência Rural, v.36, n.1, p.240-246, 2006.

LOSEKANN, M. E. et al. Alimentação do jundiá com dietas contendo óleos de arroz, canola ou soja. Ciencia Rural, v.38, n.1, p.225-230, 2008. Disponível em: <http://www.scielo.br/pdf/ cr/v38n1/a36v38n1.pdf>, Acesso em: 26/02/2013. doi: 10.1590/ S0103-84782008000100036.

MAIA, E.L. et al. Composição química e classes de lipídios em peixe de água doce Curimatã comum, Prochilodus cearensis.
Ciência Tecnologia Alimentos, Campinas, v.19, n.3, p.433437, 1999 . Disponível em: <http://www.scielo.br/scielo. php?script $=$ sci_arttext\&pid $=$ S0101-20611999000300025\&lng $=\mathrm{e}$ n\&nrm $=$ iso $>$. Accesso em: 11 set. 2012. doi: 10.1590/S010120611999000300025.

MELO, D.S. Farinha de folhas de mandioca: efeitos sobre a peroxidação e o perfil lipídico plasmático e hepático de ratos. 2005. 74f. Dissertação (Mestrado em Agroquímica e Agrobioquímica) Universidade Federal de Lavras, Lavras, MG.

MEYER, G.; FRACALOSSI, D.M. Protein requirement of jundia fingerlings, Rhamdia quelen, at two dietary energy concentrations. Aquaculture, Amsterdam, v.240, p.331-343, 2004.

MEURER, F.; HAYASHI, et al. Digestibilidade aparente de alguns alimentos proteicos pela tilápia do Nilo (Oreochromis niloticus). Revista Brasileira Zootecnia, v.32, n.6, suppl.2, p.1801-1809, 2003. Disponível em: <http://www.scielo.br/pdf/ rbz/v32n6s2/20949.pdf>. Acesso em:26/02/013. doi: <http:// dx.doi.org/10.1590/S1516-35982003000800001>.

REFSTIE, S. et al. Feed consumption and conversion in Atlantic salmon (Salmo salar) fed diets with fish meal, extracted soybean meal or soybean meal with reduced content of oligosaccharides, trypsin inhibitors lectins and soya antigens. Aquaculture, Amsterdam, v.162, p.301-312, 1998.

SANZ, A. et al. Protein nutrition in fish: protein/energy ratio and alternative protein sources to fish meal. Journal of Physiology and Biochemistry, Espanha, v.56, p.275-282, 2000.

SHARMA, S.K. et al. Food processing engineering: theory and laboratory experiments. United States of America: WileyInterscience, 2000. 348p.

SILVA, da E.M.; PEZZATO, L.E. Respostas da Tilápia do Nilo (Oreochromis niloticus) à atratividade e palatabilidade de ingredientes utilizados na alimentação de peixes. Revista Brasileira de Zootecnia, Viçosa, v.29, n.5, p. 1273-1280. 2000. Disponível em: <http://www.scielo.br/scielo.php?script=sci artte $\mathrm{xt} \& \mathrm{pid}=\mathrm{S} 151635982000000500003 \& \ln \mathrm{g}=\mathrm{en} \& \mathrm{nrm}=\mathrm{iso}>$. Acesso em: 23 out. 2011. doi: 10.1590/S1516-35982000000500003.

SKONBERG, D.I. et al. Color and flavor analyses of fillets from farm-raised rainbow trout (Oncorhynchus mykiss) fed lowphosphorus feeds containing corn or wheat gluten. Aquaculture, Amsterdam, v.166, p.269-277, 1998.

SMITH, R. et al. Aerobic mesophilic sporeforming bacteria Department of Microbiology, University of Reading, n.559, p.359-366, 1946.

WALTON, P.A. et al. Import of stably folded proteins into peroxisomes. Molecular Biology of the Cell, v.6, p.675 - 683, 1995. Disponível em: <http://classes.biology.ucsd.edu/old.web.classes/ bicd118.WI06/lectures/Week9.pdf`. Acesso em: 31 ago. 2012.

WILSON R.P. Amino acids and proteins. In: HALVER, J.E.; HARDY, R.W. Fish nutrition. 3.ed. NewYork: Academic, 2002. p.143-179. 